\title{
Arquivos imateriais: desafios da criação no contexto digital Editorial
}

No ATUAL CENÁRIO DE PRODUÇão HÍBRIDA, PRINCIPALMENTE NO CAMPO ARTísTICO, OBSERVAMOS A PROCESSUALIDADE presente nos próprios meios tecnológicos a integrar a malha processual dos objetos de criação - mesmo aqueles entendidos como analógicos - e a problematizar a noção de objeto no âmbito da crítica. Diante disso, como a reflexão sobre a criação em suas mais diversas vertentes pode contribuir para uma crítica sobre os fenômenos de produção e experimentação permeados pelas novas mídias? Como esses meios e os procedimentos de pesquisa, interação e criação se inserem nos esforços da crítica genética? Estas foram as perguntas, todas elas convergentes à ideia de imaterialidade, que nos levaram a propor o presente dossiê.

O problema da imaterialidade não é uma novidade da cultura digital. Vale lembrar que foi nos ditos iniciais da cibernética e do estabelecimento da era da informação que passamos a falar com mais recorrência sobre uma "cultura imaterial". Se a predominância do digital enfatiza o que naturalizamos como "imaterial", os estudos que compõem a $44^{\mathrm{a}}$ edição da Manuscrítica reforçam, através do olhar de artistas e de pensadores de diferentes áreas, um cenário contemporâneo caracterizado, mais do que nunca, por uma "cultura materializadora" ${ }^{1}$ na qual o ato de informar - compreendido como um ato de dar forma à matéria -, amplia seu sentido para uma prática colaborativa entre sujeitos múltiplos e emergentes.

Arquivos Imateriais são, sobretudo, uma provocação. Diante dos vários arquivos gerados, trocados, compartilhados, armazenados, transmitidos diariamente, os limites entre criar, comunicar e veicular se confundem, mas, ao mesmo tempo, dão forma a um cenário de materialidades e reflexões que se engendram na ação comunicativa. É nesse sentido que as características de transformação e de continuidade dos arquivos demonstram sua vertente como manifestação criativa e pensamento em curso de construção.

Os trabalhos que compõem a presente edição demonstram como diversas abordagens teóricas e perspectivas - de relatos de processo à crítica genética e crítica de processos de criação; da filologia à educação - lêem, interpretam e se apropriam das novas formas de expressão, podendo, portanto, contribuir com possibilidades prolíficas de análise, estas também em construção. Assim, com a ajuda dos autores, logramos compor uma edição que reflete e se interroga acerca de seu próprio lugar na produção e difusão de conhecimento, que pensa a si mesma como mediadora de um processo em grupo, dinâmico e dialógico, que vai - e precisa ir - além do exposto na materialidade. Os textos aqui reunidos, cada um deles à sua maneira, apresentam manifestações possíveis desses arquivos imateriais que compõem o nosso fazer.

O grande número de submissões de artigos de qualidade foi uma grata surpresa. Esse fato nos leva a acreditar na grande relevância e urgência das discussões sobre Arquivos Imateriais na crítica genética e na crítica de processos de criação. Além disso, a consideração do trânsito entre o analógico e o digital e do paradigma computacional como procedimento de criação, interação e remediação ${ }^{2}$ adiciona camadas à complexidade dos processos que, por sua vez, desafiam os estudos da crítica genética. A seguir, breves comentários sobre as seções desta edição e seus respectivos conteúdos.

Pela primeira vez, uma edição de Manuscrítica traz um artigo elaborado por um grupo no contexto dos trânsitos digitais, propondo uma metalinguagem do exercício acadêmico: Queimar e Postar: materializar arquivos imateriais tem como autores os membros do Grupo de Estudos em Processos de Criação da PUC-SP, do qual também fazem parte os editores que subscrevem este dossiê, e cumpre a função de introduzir as discussões propostas pela Manuscrítica \#44 - não apenas por eleger como objeto de estudo o trabalho de Carlos Vergara e seus desdobramentos nas redes, mas porque o próprio texto foi construído no curso de conversas e trocas estabelecidas em ambientes on-line. Dessa maneira, a seção "Prelúdio" é inaugurada com um

\footnotetext{
${ }^{1}$ FLUSSER, Vilém. O mundo codificado: por uma filosofia do design e da comunicação. São Paulo: Cosac Naify, 2007.

${ }^{2}$ BolTER, J. Davis; Grusin, R. Remediation: understanding new media. Cambridge: MIT Press, 2000.
} 
artigo que introduz a proposta da Manuscrítica \#44 não apenas com seu tema, como na própria forma de produção, exemplificando assim o que nós, editores, pretendemos com esta edição.

Os artigos que compõem a sessão “Ateliê” foram agrupados pelas afinidades dos temas abordados. Os três primeiros tratam sobre processos de criação literária, começando por A escritora Hilda Hilst, o editor Massao Ohno, as artes literárias e o fazermemória nos fluxos digitais que pensa a importância dos acervos bibliográficos da escritora e do editor na elaboração de memória e das interações das artes literárias nos ambientes digitais. "O lírico-ciborgue de Angélica Freitas: googlear para simular" reflete sobre as interações entre corpo e máquina no fazer literário e Da avalanche lírica em redes sociais: remediações poéticas em Snow, de Shelley Jacks observa o potencial de elaborações artístico-literárias inseridas nos trânsitos e limites das redes.

$\mathrm{O}$ trio de artigos subsequentes examina as interações entre as artes visuais e os meios digitais. Criar sob o signo da imagemtécnica: uma leitura de Videodrome e Marília Garcia pensa a produção de subjetividades na contemporaneidade, considerando os regimes de virtualização e digitalização entre os sujeitos e as tecnologias de comunicação; Inteligência artificial aplicada à criação artística: a emergência do novo artífice propõe considerações sobre a criatividade artística na dimensão artificial, experimentadas numa dinâmica de cocriação, e Sarau Virtual: Conceitos Spinozianos e Deleuzeanos no Ciberespaço analisa a experiência de criação e exposição de trabalhos artísticos por meio do projeto de extensão "Sarau Virtual Mande Notícias”, realizado em 2020, durante a pandemia de Covid-19, na Universidade Federal do Oeste da Bahia (UFOB).

Discussões sobre práticas educativas formam o escopo dos artigos que integram o terceiro agrupamento da seção. A rasura não visível capturada em processo de escrita colaborativa na sala de aula intenta, a partir de uma análise microgenética, estudar rasuras não visíveis em processos de produção de textos de alunas recém-alfabetizadas do $1^{\circ}$ ano do ensino fundamental; Plataforma ELO e autoria docente: novos horizontes às práticas pedagógicas no ensino híbrido discorre sobre o sistema ELO e oportuniza a criação, o armazenamento e o compartilhamento de Recursos Educacionais Abertos em plataformas de autoria aberta no ensino híbrido; encerrando o bloco, o artigo Conexões e interações do processo de criação no ensino remoto do design: fluxo e trânsito entre documentos de processo na disciplina projeto sentir examina aspectos que formam a complexa rede da criação no trânsito entre documentos de processo analógicos e digitais desenvolvidos no contexto do ensino remoto da disciplina Projeto Sentir do curso de design no Centro Universitário Senac - Santo Amaro, no ano letivo de 2020.

Os últimos três artigos de "Ateliê" discorrem sobre design e artes manuais, filologia editorial e jornalismo. Criação em rede: entrelaçamentos entre processos manuais de criação, 'faça você mesmo' e compartilhamento em plataformas digitais analisa a recente popularização de ideais como a autonomia, a manualidade e o "faça você mesmo" atrelados aos processos de criação na arte e no design, em diálogo com a cultura das redes; A filologia editorial na era digital propõe repensar e rever a práxis filológica de edição de textos pelas interfaces das Críticas - Textual, Genética e Sociológica - nos ambientes digitais. Encerrando a seção, o artigo A união entre o longform e o jornalismo literário busca, a partir de uma abordagem inicial da Semântica Discursiva e considerando a possível contribuição da Crítica Genética, examinar reportagens de cunho literário do site revista piaú.

Na seção “Diálogo" trazemos uma entrevista com o artista visual Rodrigo Branco que, com suas falas, demonstra a função ampla e a potência geradora dos arquivos: como estes se comportam no trânsito entre linguagens e nas relações que o sujeito, o agente criador, estabelece com os recursos materiais e imateriais que tem à sua disposição, fazendo da imagem o produto de camadas diversas e sucessivas intervenções; a solução visível e possível às demandas de uma memória cuja construção permanente se entrelaça aos documentos de processo.

A seção "Fac-símile" contempla três relatos de processo que oferecem, cada qual à sua maneira, estratégias e teorias implícitas ao fazer criativo. Como verdadeiras filosofias da composição ${ }^{3}$ contemporâneas, eles são entendidos por nós como valiosos documentos de processo para a análise do pensamento criador com base nas práticas artísticas e comunicativas. A

\footnotetext{
${ }^{3}$ PoE, Edgar Allan. A Filosofia da composição. In: BARroso, Ivo (org.). “O Corvo” e suas traduções. Rio de Janeiro: Lacerda Editores, 2000.
} 
complexidade dos documentos e dos discursos apresentados nesses relatos desafiou-nos a repensar os formatos da Manuscrítica, de maneira que resolvemos manter os textos em suas dimensões originais. Assim, A construção da memória cultural em um contexto histórico mutante: a experiência do FILEALIVE apresenta a construção da memória digital do FILE (Festival Internacional de Linguagem Eletrônica), colocando em foco questões e abordagens conceituais e técnicas e as parcerias implicadas na sua atual fase de organização como um grande arquivo digital. Já o trabalho Vestígios de memórias, camadas de esquecimento: o arquivo como construção poética revela o arquivo como uma estratégia de produção poética a partir do diálogo entre diferentes linguagens, resultando num processo de significação e expansão do próprio arquivo. "e-Imigrações como um work in progress" deixa em evidência alguns dos desafios e aspectos contemporâneos da criação literária no digital. Desse modo, apresenta a articulação da linguagem das histórias em quadrinhos e a poesia verbal a partir das potencialidades de interação e de imersão do ambiente computacional.

A crescente digitalização e disponibilização on-line de acervos artísticos e documentais internacionais reforça a importância desses materiais na ampliação do conhecimento sobre o processo de criação de artistas e obras tradicionais e reconhecidas. Desse modo, na seção “Tradução” apresentamos Acessiveis escritos de Edvard Munch (1863-1944): o manuscrito MM $N$ 122, tradução do noruegês ao português, de um dos manuscritos do artista que foram recentemente disponibilizados online pelo Museu Munch.

Agradecemos a todos os autores, aos atentos e solícitos pareceristas, especialmente à professora Dra. Cecilia Salles, bem como aos membros do comitê editorial e da equipe técnica da Revista Manuscrítica, cujos trabalho e auxílio possibilitaram esta edição. 


\author{
Manuscrítica \\ Revista de Crítica Genética
}

São Paulo n. $44 \cdot 2021$

\title{
Conselho Editorial
}

Alícia Duhá Lose (Universidade Federal da Bahia)

Aline Novais de Almeida (Associação de Pesquisadores em Crítica Genética)

Aparecido José Cirillo (Universidade Federal do Espírito Santo)

Aurèle Crasson (Institut des textes et manuscrits modernes)

Cecília Almeida Salles (Pontifícia Universidade Católica de São Paulo)

Carla Cavalcanti e Silva (Universidade Estadual Paulista)

Claudia Amigo Pino (Universidade de São Paulo)

Edson do Prado Pfützenreuter (Universidade Estadual de Campinas)

Erica Durante (Brown University/EUA)

Graciela Goldchluk (Universidad Nacional de La Plata)

Josette Monzani (Universidade Federal de São Carlos)

Lea Hafter (Universidad Nacional de La Plata)

Mabel Meira Mota (Universidade Federal da Bahia)

Márcia Ivana Lima e Silva (Universidade Federal do Rio Grande do Sul)

Márcia Edlene Mauriz Lima (Universidade Estadual do Piauí)

Marcos Antonio de Moraes (Universidade de São Paulo)

Maria Eunice Moreira (Pontifícia Universidade Católica do Rio Grande do Sul)

Maria da Luz Pinheiro de Cristo (Universidade Federal do Espírito Santo)

Maria Soledad Falabella (Universidad de Chile)

Max Hidalgo Nácher (Universitat de Barcelona)

Miguel Rettenmaier (Universidade de Passo Fundo)

Moema Rodrigues Brandão Mendes (Centro Universitário Uni Academia e Fundação Casa de Rui Barbosa)

Mônica Gama (Universidade Federal de Ouro Preto)

Patricia Kiss Spineli (Pontifícia Universidade Católica de São Paulo)

Paolo D'Iorio (Institut des textes et manuscrits modernes, CNRS. École normale supérieure de Paris)

Philippe Willemart (Universidade de São Paulo)

Rosa Borges (Universidade Federal da Bahia)

Sérgio Romanelli (Universidade Federal de Santa Catarina)

Sílvia Maria Guerra Anastácio (Universidade Federal da Bahia)

Telê Ancona Lopez (Universidade de São Paulo)

Viviane Araújo Alves da Costa Pereira (Universidade Federal do Paraná) 


\section{DIAGRAMAÇÃo}

Yasmin Ferreira Chinelato

\section{ILUSTR AÇÕES}

Capa: Camila Mangueira.

Manuscrítica é uma publicação da Associação de

Pesquisadores em Crítica Genética (APCG) e da Pós-

Graduação em Letras Estrangeiras e Tradução

Universidade de São Paulo com o apoio da CAPES

\section{DIRETORIA APCG}

Presidente - Edson do Prado Pfützenreuter (Unicamp)

Vice-presidente - Patricia Kiss Spineli (PUC-SP)

Membro honorário da APCG - Léa Hafter (Universidad

Nacional de la Plata)

Tesoureira - Katerina Blasques Kaspar (USP)

Secretário Geral - Leonardo Mendes (USP)

Secretária de divulgação - Amayi Koyano (USP)

$1^{\circ}$ suplente: Aline Novais de Almeida (USP)

$2^{\circ}$ suplente: Thiago Leão Antunes (USP)

3o suplente: Wagner Miranda Dias (PUC-SP)

\section{EDITORES DESTE NÚMERO}

Camila Mangueira (Faculdade de Belas Artes da

Universidade do Porto)

Paula Martinelli (PUC-SP)

Wagner Miranda Dias (PUC-SP)

\section{EQUIPE EDITORIAL}

Aline Novais de Almeida

Amayi Koyano

Edson do Prado Pfützenreuter

Katerina Blasques Kaspar

Léa Hafter

Leonardo Mendes

Patricia Kiss Spineli

Thiago Leão Antunes

Wagner Miranda Dias

\section{E-MAIL:}

manuscritica@gmail.com

Novo portal da revista:

www.revistas.usp.br/manuscritica

\section{UniversidAdE DE SÃo PAUlo}

Programa de Pós-Graduação em Letras Estrangeiras e Tradução

Coordenadora da Pós-Graduação: Eliane Lousada

Vice-coordenadora: Adriana Zavaglia 